\title{
The LDHEN hive mind: Learning development in UK higher education as a professional culture
}

\author{
Katharine Stapleford \\ University of Leeds, UK
}

\section{Abstract}

The Learning Developer in higher education (HE) works with students to help them make sense of the language and practices of HE. It is a relatively new role and has grown in response to the Widening Participation agenda which has seen an increase in entry of 'non-traditional' students into HE. Learning developers' job descriptions, employment contracts and institutional location vary between institutions and the role is often misunderstood across academia. There has long been discussion and debate within the learning development community regarding the professionalisation of the role and what this might look like. The literature in this area is sparse and to date consists of small-scale surveys of learning development practitioners with inconclusive findings. This study aims to contribute to our understanding of learning developer professional identity by analysing six months of discourse from the Learning Development in Higher Education Network (LDHEN) Listserv. This is explored through the lens of social identity theory and findings suggest that the learning development community functions as a professional culture based on collegiality, trust, shared values and a protected collective knowledge base. This attitudinal perspective of professional identity as professional culture is proposed as a more productive approach to the debate than more traditional interpretations of professionalism based on qualifications and formal training.

Key words: Learning development; professional identity; distributed communities of practice; professional culture; social identity.

\section{Introduction}


I am a learning developer in a UK HE institution. The role of the learning developer in UK $\mathrm{HE}$ is 'to work with students to help them make sense of the seemingly mysterious and alienating practices of academia' (Hilsdon, 2011, p. 16), in other words, to improve the student learning experience. However, when I am asked about my work, my response rarely does justice to this complex and nuanced role; often I resort to reductive and simplistic descriptions such as 'I teach study skills' or 'I help students write essays and reference correctly', usually with a sense of guilt and letting the side down. This paper is the result of my drive to better understand the reasons behind this lack of professional recognition and an attempt to gain a sense of ownership and clarity around the learning development professional identity.

\section{Learning development in $\mathrm{HE}$}

Learning Development (LD) arose largely in response to the Widening Participation agenda in UK HE during the late 1990s, particularly in the wake of the Dearing Report (1997) recommendations to facilitate an increase in participation in HE. The resultant drive to increase access for lower socio-economic groups (Greenbank, 2006) meant that there was a need for services to meet the needs of 'non-traditional' students who lacked the cultural capital and habitus (Bourdieu and Passeron, 1990) of the traditional more affluent HE entrant with an academic background. LD provided a response to this need and thus is grounded in a social emancipatory philosophy (Sinfield et al., 2011). This ethos constitutes a fundamental element of LD identity, it is what distinguishes the practice from 'study skills' and 'learning support', it is about creating a positive student experience rather than a deficit approach to 'fixing' the student. In this way, it plays a key role in creating a sense of belonging for students highlighted in the What Works programme (Thomas, 2002). However, LD practitioners and the students they work with '[occupy] a dichotomous position: needed in HE to meet government targets - but still not wanted by "the academy"' (Sinfield et al., 2011, p. 54).

The professional standing of learning developers is a key concern within the community, as LD contracts, terms and conditions and physical presence vary widely among institutions (Murray and Glass, 2011). This inconsistency results in a lack of understanding of LD as a profession (Silvey et al., 2018, Hilsdon, 2011) and arguably leads to vulnerability, isolation and frustration among LD practitioners. Furthermore, there is little in 
the way of professional training, LD qualifications or clear career progression (Webster, 2017). Learning developers are not alone in this phenomenon; academic developers, librarians and administrator/managers often work in hybrid professional/academic or 'third spaces' (Whitchurch, 2008) which 'lack a unifying professional identity' (Handal, 2008, p. 55). Since its inception, there has been uncertainty as to whether LD is a community or a profession (Murray and Glass, 2011). While it is a 'paid occupation', thereby fitting the simple definition of profession, there is no 'prolonged training and a formal qualification' as per the extended definition in the Oxford Dictionary of English (2010, profession entry). There is little doubt that most learning developers are professional in that they are educated beyond degree level and generally enter LD from other careers (Murray and Glass, 2011, pp. 36-37). However, according to external definitions, they are professional 'other', not professional learning developers. Despite, or perhaps because of this, the LD community is vibrant, with a strong sense of identity, professionalism, mutual support and interaction, thereby suggesting that it is not necessary to be deemed a profession by external standards, in order to have a strong professional identity. Indeed, Johnson (2018, p. 18) concludes that internal affirmation of LD values is needed to "permeate into the wider academic community', indicating that a reconceptualisation is needed.

\section{The Learning Development in Higher Education Network}

The LD community is represented by the Association for Learning Development in Higher Education (ALDinHE). ALDinHE supports learning developers by facilitating discussion and debate, sharing practice and promoting LD values, namely:

- Working alongside students to make sense of and get the most out of HE learning

- Making HE inclusive through emancipatory practice, partnership working and collaboration

- Adopting and sharing effective Learning Development practice with (and external to) our own institutions

- Critical self-reflection, on-going learning and a commitment to professional development

- Commitment to a scholarly approach and research related to Learning Development.

(Association for Learning Development in Higher Education, n.d.) 
This is achieved largely through the Learning Development in Higher Education Network Jiscmail list or listserv (henceforth LDHEN), an active and well-used network. It was set up in 2003 by a small group of like-minded learning developers as a support network for practitioners working in this new and often isolated role (Hilsdon, 2011). Since then it has grown significantly and now has 1335 subscribers.

The LDHEN functions as a distributed community of practice. Based on Lave and Wenger's (1991) Communities of Practice theory, the notion of distributed communities of practice (DCoP) takes account of the dispersed nature of many professional communities which are sustained through computer technology (Sato et al., 2008). DCoP differ from virtual learning communities in that they are less formal, voluntary, self-starting, needsdriven and tend to have a stronger sense of identity (Schwier and Daniel, 2008). While there exists a significant body of literature investigating virtual and online learning communities in education, research into DCoP, particularly within $\mathrm{HE}$, is less plentiful.

It is the aim of this paper to contribute to our understanding of LD professional knowledge, practices and values through an investigation of the LDHEN DCoP. By illuminating how professional identity is reified in the LDHEN, this study offers insights into the professional identity of the traditionally undervalued and unrecognised 'academic-professional hybrid role' (The Guardian, 2017). Gaining a deeper theoretically informed understanding of the relationship between the LDHEN DCoP and the professional identity of its members will illuminate what it means to be a professional learning developer and help practitioners articulate and advance their professional standing within the wider HE community. This in turn can encourage similar 'new professions' to gain support, confidence, and direction from such communities by engaging more meaningfully in the development of their professional identity.

\section{Literature and theoretical framework}

\section{Distributed Communities of Practice}

The majority of DCoP featuring in the literature concern formally established communities with a specific educational goal, usually professional development, and with an evaluative focus to the research (Goodyear and Steeples, 1998; Hew and Hara, 2008; Klecka et al., 
2004; Steeples and Goodyear, 1999). However, some studies explore the more commercial arena (Hildreth et al., 2000) or the potential of DCoP as emancipatory tools for social change (Quintana and Morales, 2015). A focus on the practical aspects of providing a platform for communication between geographically dispersed colleagues features in several studies (Beaumont et al., 2009; Dimitrova et al., 2015) although these studies also found significant affective and social impacts. This affective factor often provides the impetus for the establishment of DCoP, for example support networks for caregivers (Lucas, 2011) and parents of children with autism (Lazaro et al., 2014). Information, resource and knowledge sharing (Kurtz-Rossi et al., 2017) and knowledge construction, particularly reifying tacit knowledge (Goodyear and Steeples, 1998; Hildreth et al., 2000), is a key theme in the literature, with a particular emphasis on the need for trust as a precursor to collaborative knowledge building (Beaumont et al., 2009; Daniel et al., 2003). The contexts for much of the empirical research in this area are medical and healthcare settings. Although a number of studies come from the field of education, particularly teacher professional development (Klecka et al., 2004, Neukrug et al., 2010, Parker and Bowell, 1998, Pennington and Graham, 2002, Pennington et al., 2004, Spitzer and Wedding, 1995), research into DCoP for staff in HE is scarce.

Whether explicitly stated, for example Daniel et al.'s (2003) social capital and Quintana and Morales' (2015) distributed leadership, or implicit in the nature of the research, there is a tendency towards socio-cultural approaches in the literature. This is to be expected considering the social nature of communities of practice. However, there is a lack of rigorous theoretical underpinnings to this particular body of literature generally and $\mathrm{HE}$, in particular, remains under-represented. Therefore, this study aims to offer a theoretically informed analysis of the LDHEN DCoP in order to extend our understanding of this context.

\section{Professional identity}

There is no shortage of literature in the area of professional identity, particularly teacher professional identity, and the notion of professionalism remains a popular construct within the field of education, it seems, in response to the recent political and economic changes in the field. However, a lack of unity and agreement regarding understandings, definitions and applications of professional identity persists (Beauchamp and Thomas, 2009). 
Given the lack of agreement of the meaning of the term and the many and varied interpretations of 'profession', Evetts (2003, p. 398) suggests a refocussing from a preoccupation with definitions of profession, to an examination of the 'appeal of the concepts of 'profession' and particularly of 'professionalism". She concludes that professionalism's appeal lies in the sense of practitioner agency in terms of knowledge and collegiality (p. 407), while the reality for many professionals is one of economic constraints and accountability. Indeed, along with the marketisation of education, the idea of professional and professionalism has undergone a shift away from traditional notions of practitioner autonomy, control and public status to accountability to external agencies and quality of practice (Evetts, 2003; Evans, 2008). In contrast, practitioners retain some control argues Helsby, (1995, p. 320 as cited in Evans, 2008, p. 23) who makes the point that professionalism is a social construct and as such, practitioners can shape it from within.

Similarly, Evans (2008) makes a case for the notion of professional culture, which emphasises the attitudinal and collective nature of professionalism, or 'professionality', which she defines as 'an ideologically-, attitudinally-, intellectually- and epistemologicallybased stance on the part of an individual, in relation to the practice of the profession to which s/he belongs, and which influence her/his professional practice' (Evans, 2002b, pp. 6-7, as cited in Evans, 2008, p. 26). This definition aligns with Hoyle's (1975) model of 'extended' professionality, which moves beyond everyday practice to the underlying mindset (cited in Evans, 2008). This perspective encapsulates well, the professionality of the learning developer whose practice, as we have seen, is very much values-based ideologically-oriented.

Building on this idea of professional culture and extended professionality, Johnson (2018, p. 18) highlights the importance of 'growing the collective voice' from within the LD community in order to broaden recognition and understanding of LD values across academia rather than attempting to conform to external ideas of professionalism. It is the intention of this study to examine the 'collective voice' of the LD community, that is, the LDHEN, in order to augment the body of knowledge on LD professional identity and offer a reconceptualisation from a professional culture perspective. 


\section{Social Identity Theory}

In the context of professional identity, Barbour and Lammers (2015) differentiate between belonging as simple membership and attachment as a more emotional connection. With regard to LDHEN, we can take belonging as a given as all subscribers are by definition members, therefore I adopt a broader definition of belonging and attachment in terms of a sense of belonging which derives from/leads to the emotional attachment. This reflects Tajfel's (1982, p. 2) claim that group identification requires cognitive and evaluative components and often an emotional investment in these. Social identity, according to Tajfel, is 'the individual's knowledge that he [sic] belongs to certain social groups together with some emotional and value significance to him [sic] of the group membership' (Tajfel, 1972, p. 31 as cited in Turner, 1982, p. 18). It is based on the notion of intra- and intergroup attitudes and behaviours which are primarily determined by self-definition (Tajfel, 1974, p. 67), thus it aligns well to the attitudinal and collective interpretation of professionality discussed in the previous section.

Although much of Tajfel's work on social identity is concerned with prejudice and conflict in terms of national and ethnic identity (Spears, 2011), the premise upon which the construction of social identity is built is a relevant one for investigations of professional culture. A profession is necessarily a group, and we often define ourselves by our employment, which, in turn plays a significant role in determining our socio-economic status. Moreover, Turner's (1982, p. 15) broader definition: 'a social group can be defined as two or more individuals who share a common social identification of themselves or... perceive themselves to be members of the same social category' is particularly appropriate for the current investigation as is emphasises personal agency rather than relying on external labels. Not everybody who subscribes to and participates in LDHEN has a learning development job title, but they come together under the auspices of LDHEN and share the 'common social identification of' learning developer, that is, they all must 'perceive themselves to be' learning developers in some sense at the time of participating. This temporary state, reflects Tajfel's (1974) point that identity is a dynamic rather than a static state of being as with the concept of professionalism (Evans, 2008).

Tajfel presents a sequence of four concepts to explain social identity: 'social categorization, social identity, social comparison and psychological distinctiveness' (1974, p. 69). Social categorisation denotes the classification of the social world; social identity 
places the individual into one of these categories; social comparison refers to the individual's sense of identity in relation to other categories of which the individual is not a member, and psychological distinctiveness promotes the individual's positive self-image resulting from the 'positively valued distinctiveness from other groups' (Cairns, 1982, p. 285). Underpinning this sequence are the notions of secure and insecure social identity and superior and inferior groups. Individuals desire a positive social identity, which psychological distinctiveness provides, however, if one's group is socially inferior or devalued, then their positive social identity is threatened or insecure (Spears, 2011, p. 207). In this situation, the inferior group and the individual make recourse to a range of strategies to reclaim the positive social identity, one such strategy being 'social creativity' by which the inferior traits are reframed in a more positive light and embrace the inferior traits as drivers to enact social change (Tajfel, 1974).

In this study, I investigate the professional culture of learning developers with reference to these social identity processes and concepts in order to provide insights into the nature of LD identity and the potential for social change. The research questions guiding this study are:

1. How is the professional culture of Learning Developers reified through the LDHEN Listserv?

2. What are the implications for the learning development community?

\section{Methodology}

\section{Data collection}

The data consists of the text-based interactions occurring on the LDHEN discussion list during a six-month period from September 2017 - February 2018. These are publicly available from the Jiscmail Listserv archives. For each month in the archives I extracted the table of contents in order to identify discussion threads which met two criteria: firstly, the subject indicated a discussion topic rather than a simple announcement or administrative/technical query; secondly, the thread consisted of at least three messages, in order to constitute a discussion or extended interaction. This selection resulted in 35 separate discussion threads each comprising between three and 19 messages. 


\section{Analysis}

As noted in the introduction, I am a learning developer and a member of the LDHEN DCoP; I have insider knowledge of the community, its members, its priorities and agendas. As such, I am a 'complete member researcher' (Adler \& Adler, 1987 as cited in Dwyer and Buckle, 2009, p. 55). While I acknowledge that this insider status has the potential to influence interpretation and analysis of results (Dwyer and Buckle, 2009, p. 58), more importantly it can provide a deeper understanding from which to explicate the findings. The unit of analysis was a complete thought or idea expressed, rather than the whole post or message. As the results and discussion section will show, many posts began by responding to a request for information and then proceeded to offer reflections, opinions, experiences and more tangential thoughts. I used content analysis initially to begin to organise and draw meaning from the data using a priori descriptive categories comprising the ALDinHE values; the UK Professional Standards Framework and Tajfel's (1974) social identity concepts to code the data. These were then subsumed into broader conceptual themes. I used discourse analysis to further analyse and interpret the data within each theme. Given the focus of this study on identity as experienced and expressed by the participants of the LDHEN listserv, and 'discourse is interactive identity-based communication' (Gee, 2014, p. 24), discourse analysis offers an appropriate methodological approach. Gee distinguishes between 'd/discourse' and 'D/discourse' with the latter encompassing context, associations, insider knowledge and socio-political, historical undertones. Given that these factors comprise important elements of LD professional identity as well as my positioning as insider researcher, D/discourse was my particular analytic lens.

\section{Ethics}

Ethical approval was given by the university where I am a doctoral student. Additionally, I sought permission from the LDHEN list owners, who responded that the archives are public and searchable so no consent was required from the list members. I also consulted the Jiscmail terms and conditions of service to ensure there were no clauses preventing the use of content for research purposes. To provide anonymity, the participants are labelled LD 1, LD 2, etc. however these are not assigned to particular participants, rather they simply denote different contributors. 


\section{Results and discussion}

The coding of the message content revealed three prominent themes:

1. professional values and beliefs

2. belonging and attachment

3. professional knowledge and practices.

This section will present these themes illustrated by the data and interpret the discourse through a social identity lens. The excerpts from the discussions are rendered here verbatim and I have not corrected any language errors or typos.

\section{Professional values and beliefs}

The role and positioning of the learning developer

Values and beliefs regarding the role and positioning of LD are expressed in conversations explicitly on this topic such as requests for literature addressing collaborative working and leadership and discussions on the hybrid nature of the role. These discussions often lead to critically reflective responses regarding recognition and professional standing as well as references to external scholarly sources, which are critically evaluated with reference to personal career experiences, such as the following:

LD 1: Celia Whitchurch's work is certainly very interesting - though it explicitly excludes library and information professionals. I have been a member of a course team, have published, am a PFHEA and am still largely professionally defined in the UK Higher Education sector by what I am not!

LD 2: I feel this. I have just moved to a PSS role and I can't see where the career progression is for me. It's a bit of a minefield. I can also see these hybrid roles increasing as the work we do diversifies. I certainly know of colleagues (the library for instance) who have great publication records and also do some teaching but they are not on similar academic pay grades. 
When viewed in the context of the long-term uncertainty around the LD role, these comments reflect the social categorisation and social identity concepts. Firstly, while LD 1 is not by definition a learning developer, she is a library and information professional, her active participation in the LDHEN list implies a level of self-determination as a learning developer, and that the group is meaningful to LD 1 and contributes to her self-image. Her final remark, suggests a degree of resentment or hostility towards the UK HE sector outgroup thus strengthening the LD in-group affiliation and providing a positive social identity through psychological distinctiveness. Similarly, LD 2 highlights the group value of the hybrid colleagues, against the implied system who do not recognise the value of such roles in terms of salary, despite their perceived worth resulting from publication records. Some understanding of the current policy background in UK HE with regard to the focus on publishing and the funding attached to the Research Excellence Framework can shed further light on these sentiments. The undervalued learning developer, while contributing to this cause, is still seen as lesser than 'academic' counterparts. These examples illustrate social creativity in that the inferior traits are represented in a more positive light: the system, or out-group, while holding the power, is presented negatively, while the undervalued learning developer adopts a higher moral position.

Further debate arising from values and beliefs regarding the role of the learning developer, are seen in discussions of the use of external (both to LDHEN and academia generally) services, for example in response to an enquiry about recommending proof readers to students. First, the initial enquiry is tentative and adopts a seeking permission tone after justifying and explaining their rationale in some detail:

It seems like there are cases - after other strategies have been tried - when it is appropriate to suggest that a student uses the services of a commercial proofreader to highlight 'surface' errors in their work, e.g. spelling, grammar, ambiguous sentences.

Of course, there are boundaries: the student must seek the tutor/supervisor's permission; the proofreader must annotate the text in such a way that the student can decide whether or not to accept each suggested change; no changes must be made to the meaning, ideas or argument, and so on. 
Again, some insider knowledge of the LD background and its aversion to the deficit model of 'fixing' students' mistakes, is important to acknowledge here. The caveats, qualifications and careful presentation of the question is a clear indication of the enquirer's awareness of this sensitive issue. Responses equally recognise the deeper philosophies in question:

LD 1: So my answer is no. After all, as learner developers, what are we trying to develop?

LD 2: I think YES [...] Also, isn't it our job as learning developers to support learning rather than communication?

Both responses refer to the role or 'job' of LD which is differently interpreted at a fundamental level. This might beg the question of whether there is agreement as to the professional identity of LD or whether this is an indication of learning developers as professionals, with strong attachment to (their interpretation of) the professional values. It is important to note here, that this is the only example of a direct disagreement between members in the six months of discussions analysed and, on the whole, the community displays high levels of agreement and in-group affiliation. Nonetheless, it is perhaps an indication of the 'self-definition' Tajfel notes is a necessary precursor to in-group out-group attitudes and behaviours.

\section{Social emancipatory function}

Much more prevalent are instances of shared professional values and beliefs in response to external artefacts, often academic journal articles or newspaper articles, which are posted for the purpose of garnering professional responses thus:

LD 1: I think we need to understand other cultures ways of knowing and understanding in order to scaffold students in the acculturation process rather than seeing them as deficit.

LD 2: Hi [name] - couldn't agree more on both points - as to homogenisation and limited notions of criticality (and decolonisation of such?)

LD 3: Yes [name], [name] - huge agreement from me too: the political, social and ideological contexts of 'Western' 'critical' 'thinking' need some serious interrogation! LD 4: To me, one very interesting aspect of this is how come, despite our very 'Western' trumpeting of inclusive education, the welcoming of diversity, and a claimed 'criticality' that apparently questions all claims for knowledge and truth, we 
are still (I'm thinking of education generally, not individual practitioners!) taking profoundly deficit - and othering - views of learners we deem to be 'different'....

These more cohesive perspectives move beyond cognitive principles to more personal shared social and political values. Once more, insider knowledge confirms that sentiments are shared by many learning developers and mediate the social emancipatory underpinnings of the ALDinHE professional values generally and Value 3 specifically: 'Making HE inclusive through emancipatory practice, partnership working and collaboration.' (Association for Learning Development in Higher Education, 2018). This provides grounding for in-group hostility towards colonial and Western hegemonic deficit views of the non-traditional student, which the LD community would appear to distance itself from. Furthermore, the apparent contradiction pointed out by LD 4 of the superficial inclusiveness of HE which is not borne out in practice is reminiscent of the 'dichotomous position' (Sinfield et al., 2011) of LD pointed out in the introduction to this paper.

\section{Belonging and attachment}

Individuals' sense of belonging is a strong theme running through all of the discussion threads. This is often signified in the salutations which have an informal tone and explicitly state the professional yet social relations felt by members:

\section{LD 1: Dear LD colleagues and friends \\ LD 2: Good Afternoon Fellow LD-ers! \\ LD 3: Dear folks,}

Several posts also make use of emoticons and abbreviations which has the effect of signalling social presence and a sense of familiarity. Social presence is also seen through the sharing of personal information, asides and anecdotes to illustrate points or extend others' contributions with several posts beginning 'I... was reminded of'. The following excerpt demonstrates a level of trust as well as familiarity with the community etiquette and norms by sharing this anecdote:

LD 1: Thanks for that - I always regret not having taken a pic of an elderly couple seated opposite me on a train journey once. One was reading from a hard-copy paperback - the other from a Kindle - kind of 'analogue meets digital.' (-) 
Although it is related to a discussion thread on ebooks v. print, the anecdote is an aside and arguably serves a purely social purpose in that it does not extend the knowledge construction occurring earlier in the thread. It reflects a face-to-face 'water cooler moment' which are less common in virtual communities. This accords with earlier studies highlighting the affective, social aspects of DCoP and the importance of trust as a basis from which to share and construct knowledge. The perception of intensity of attachment (Barbour and Lammers, 2015) is also seen through the use of humour which suggests members feel a level of comfort and familiarity to share jokes and trivia. These data reflect the emotional significance of group membership to the individual and suggest an affective basis for group belongingness (Spears, 2011).

\section{Professional knowledge and practice}

The 'common social identification' (Turner, 1982, p. 15) is writ large in openers such as:

\section{LD 1: Hi LDHEN hive mind}

LD 2: I would like to pick the collective LD brain ...

Such phrases are frequently used when introducing requests and point to LD knowledge as distributed and common property of the community. The 'collective' is the source of knowledge rather than the individual members and the LDHEN mediates this communal intelligence. This is a particularly powerful community principle; there is a strong sense of ownership of this collective cognition, and it is protected and defended against external services, which are not privy to it and are thus viewed as imposters encroaching on the LD role. This idea of control suggests a return to the 'old-school' definitions of professionalism (Evans, 2008). The extracts below are from discussions on so-called 'Essay mills' and online skills development services:

LD 1: I found the email quite amusing as learning development is perhaps the polar opposite of their whole business model so they had no chance of success in emailing me. It was also so poorly formatted and structured, I would question the quality of any work they would produce. I leave this here for your amusement: [+link]

LD 2: I can't decide if the author is too naive to be a good academic, or criminally self-deceiving, or just mendacious. The 'I was only writing model essays, it's not up to me what students do with them' defence is pathetic. 
Here is clear evidence of Tajfel's social comparison and psychological distinctiveness principles (1974). There is a desire to differentiate the LD group from the commercial businesses, describing them as 'the polar opposite' refers back to the social justice roots of LD as opposed to the capitalist goals of neoliberal corporates. The in-group disdain is unambiguous and forthright at what it perceives as the inferior ability and insidious motivations of the out-group thereby strengthening the in-group superiority and offering, for a time, a sense of secure social identity. So the changing, dynamic nature of social identity is played out in such conversations where the previously marginal social group adopts the superior position.

A significant proportion of interaction concerns sharing practice, both in teaching and administrative tasks. There is an implied assumption regarding the credibility, of the community's professional knowledge in posts starting, 'How do others approach this?' or 'Seeking advice...' or 'Any recommendations...?' 'Has anyone explored...', 'I would be grateful for any information...'. The fact that such requests receive substantial replies often with extensive detailed advice, suggestions and offers of resources and further assistance, indicates a desire to share knowledge. This is taken further to knowledge construction, when the initial enquirer collates and summarises the contributions and represents this back to the community. In fact, there is often an expectation that such knowledge will be shared suggesting the community feels it has an entitlement to this knowledge and the enquirer is obligated to share:

LD 1: If you are gathering more examples as people reply directly to you - it would be great if you shared them back to the List?

LD 2: Any comments / suggestions etc. will be gratefully received and I will (off course) collate answers.

This further corroborates the proprietary stance with regards to distributed or collective knowledge seen earlier.

Overall, the analysis of the LDHEN discourse through the social identity lens reveals that the LD identity is grounded in the social emancipatory purpose of LD; it is what informs LD 
practice and provides a source of unity. This philosophy is how LD distinguishes itself from the business model of student support and justifies its guardianship of LD knowledge.

\section{Conclusion}

This paper set out to contribute to our understanding of the professional identity of the learning developer by analysing the discourse of the LD DCoP from a social identity perspective. The questions underpinning this study concerned the reification of professional identity through the LDHEN Listserv and the implications for learning developers regarding a reconceptualisation of their professional identity. The findings that I have presented and discussed suggest that the lived professional identity of the learning developer as seen through the LDHEN interactions is a form of professional culture. The results suggest that LD culture comprises a powerful positive social identity based on collegiality, trust, shared values of social justice and a protected collective knowledge base.

\section{Limitations and further research}

It is important to note that a mere six months of discourse data offered abundant rich data of which only a relatively small portion is presented in this study. Ideally, in a longer project, 12 months of data representing a complete academic cycle would present a fuller picture. While the LDHEN Jiscmail list currently has 1335 subscribers, significantly fewer of these are active participants and as such this study cannot claim to be representative of all LD practitioners. However, it could be argued that LDHEN constitutes the essence of the LD community considering its beginnings, as discussed in the introduction, it does offer a valid perspective on the public face of learning development in UK HE and contributes to our understanding of the nature of LD identity and similar hybrid roles referred to in the introduction.

A further point to note with regard to the discourse available for analysis, is the data collection process, which does not ensure a representative sample of the LD population. The more extrovert dominant members are perhaps overly represented within the LDHEN DCoP. Therefore, it would be useful to extend this research by investigating other LD domains and a wider range of voices, for example the annual conference, regional 
symposia and shared online resources, to build a more comprehensive model of LD identity. The mediators of LD professional identity, including the Jiscmail list itself, external resources, personal beliefs and institutional and political contexts, have been alluded to within this study, but word count restrictions prevented a fuller analysis of these. Further research might therefore usefully investigate these mediators from a distributed cognition or cultural historical activity theory perspective.

Overall, this study has shown that LD professionality is reified through social identity principles of belonging, attachment, in-group affiliations as well as through distributed knowledge and a sense of guardianship of this knowledge. What is expressed through the email list is an embodiment of the social emancipatory principles on which LDHEN was founded in the form of a professional culture. By reconceptualising their professional identity as a professional culture, learning developers have recourse to a potentially more powerful and appropriate source of unity than traditional notions of qualifications and formal training. Moving forward, the LD community could further explore this notion of LD professional culture in a wider range of research contexts and theoretical frameworks.

\section{References}

Association for Learning Development in Higher Education (n.d.) About. Available at: http://www.aldinhe.ac.uk/about/ (Accessed: 17 November 2018).

Barbour, J. B. and Lammers, J. C. (2015) 'Measuring professional identity: a review of the literature and a multilevel confirmatory factor analysis of professional identity constructs', Journal of Professions and Organization, 2(1), pp. 38-60.

Beauchamp, C. and Thomas, L. (2009) 'Understanding teacher identity: An overview of issues in the literature and implications for teacher education', Cambridge Journal of Education, 39(2), pp. 175-189.

Beaumont, R., Stirling, J. and Percy, A. (2009) 'Tutors' Forum: Engaging distributed communities of practice', Open Learning, 24(2), pp. 141-154. 
Bourdieu, P. and Passeron, J. C. (1990) Reproduction in education, society and culture [electronic resource]: Sage. Available at:

http://web.b.ebscohost.com.ezproxy.lancs.ac.uk/ehost/ebookviewer/ebook/bmxlYmt

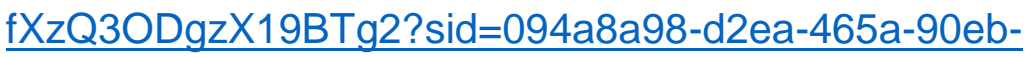
df7f105ff60b@sessionmgr101\&vid=0\&format=EB\&rid=1. (Accessed: 17 November 2018)

Cairns, E. (1982) 'Intergroup conflict in Northern Ireland', in Tajfel, H. (ed.) Social Identity and Intergroup Relations. Cambridge: Cambridge University Press, pp. 277-297.

Daniel, B., Schwier, R. A. and McCalla, G. (2003) 'Social capital in virtual learning communities and distributed communities of practice', Canadian Journal of Learning and Technology, 29(3).

Dearing Report (1997) Higher Education in the learning society Main Report: Her Majesty's Stationery Office. Available at:

http://www.educationengland.org.uk/documents/dearing1997/dearing1997.html. (Accessed: 17 November 2018)

Dimitrova, D., Mok, D. and Wellman, B. (2015) 'Changing ties in a far-flung, multidisciplinary research network: the case of GRAND', American Behavioral Scientist, 59(5), pp. 599-616.

Dwyer, S. C. and Buckle, J. L. (2009) 'The space between: on being an insider-outsider in qualitative research', International Journal of Qualitative Methods, 8(1), pp. 54-63.

Evans, L. (2008) 'Professionalism, professionality and the development of education professionals', British Journal of Educational Studies, 56(1), pp. 20-38.

Evetts, J. (2003) 'The sociological analysis of professionalism: occupational change in the modern world', International Sociology, 18(2), pp. 395-415. 
Gee, J. P. (2014) An introduction to discourse analysis: theory and method. Available at: https://ebookcentral.proquest.com/lib/lancaster/detail.action?doclD=1613825. (Accessed: 17 November 2018).

Goodyear, P., and Steeples, C. (1998) 'Creating shareable representations of practice', ALT-J, 6(3), pp.16-23.

Greenbank, P. (2006) 'The evolution of government policy on widening participation', Higher Education Quarterly, 60(2), pp. 141-166.

Handal, G. (2008) 'Identities of academic developers: Critical friends in the academy?', in Barnett, R. and Di Napoli, R. (eds.) Changing Identities in Higher Education. Abingdon: Routledge, pp. 55-68.

Hew, K.F. and Hara, N., (2008) 'An online listserv for nurse practitioners: A viable venue for continuous nursing professional development?' Nurse Education Today, 28(4), pp.450-457.

Hildreth, P., Kimble, C. and Wright, P. (2000) 'Communities of practice in the distributed international environment', Journal of Knowledge Management, 4(1), pp. 27-38.

Hilsdon, J. (2011) 'What is learning development?', in Hartley, P., Hilsdon, J., Keenan, C., Sinfield, S. and Verity, M. (eds.) Learning Development in Higher Education. Basingstoke: Palgrave MacMillan, pp. 13-27.

Johnson, I. P. (2018) 'Driving learning development professionalism forward from within', Journal of Learning Development in Higher Education, Special Edition: ALDinHE Conference 2018, pp. 1-29.

Klecka, C. L., Cheng, Y.-M. and Clift, R. T. (2004) 'Exploring the potential of electronic mentoring', Action in Teacher Education, 26(3), pp. 2-9. 
Kurtz-Rossi, S., Rikard, R. V. and McKinney, J. (2017) 'Learning from the field and its listserv: issues that concern health literacy practitioners', Information Services \& Use, 37, pp. 219-234.

Lave, J. and Wenger, E. (1991) Situated Learning: Legitimate Peripheral Participation. Cambridge: Cambridge University Press.

Lazaro, J. A., Bundy, M. B. and English, S. L. (2014) 'Qualitative themes of a listserv for parents of children with autism', International Journal on Disability and Human Development, 13(1), pp. 71-78.

Lucas, M. R. (2011) 'A private caregiver listserv: maximum benefit for minimum cost', Journal of Psychosocial Oncology, 29(2), pp. 168-174.

Murray, L. and Glass, B. (2011) 'Learning development in higher education: community of practice or profession?', in Hartley, P., Hilsdon, J., Keenan, C., Sinfield, S. and Verity, M. (eds.) Learning Development in Higher Education. Basingstoke: Palgrave MacMillan, pp. 28-39.

Neukrug, E., Cicchetti, R., Forman, J., Kyser, N., McBride, R. and Wisinger, S. (2010) 'A content analysis of CESNET-L e-mail messages: directions for information delivery in higher education', Research and Integration of Instructional Technology, 22(1), pp. 60-72.

Parker, B. and Bowell, B. (1998) 'Exploiting computer-mediated communication to support in-service professional development: the SENCO experience', Journal of Information Technology for Teacher Education, 7(2), pp. 229-246.

Pennington, T. and Graham, G. (2002) 'Exploring the influence of a physical education listserv on K-12 physical educators', Journal of Technology and Teacher Education, 10(3), pp. 383-405.

Pennington, T., Wilkinson, C. and Vance, J. (2004) 'Physical educators online: what is on the minds of teachers in the trenches?', Physical Educator, 61(1), pp. 45-56. 
Quintana, M. and Morales, A. (2015) 'Learning from listservs: collaboration, knowledge exchange, and the formation of distributed leadership for farmers' markets and the food movement', Studies in the Education of Adults, 47(2), pp. 160-175.

Sato, G. Y., Barthes, J. P. and Chen, K. (2008) 'Following the evolution of distributed communities of practice'. Proceedings of the Seventh IEEE International Conference on Cognitive Informatics, ICCI 2008, Stanford University, California, USA, 14-16 August.

Schwier, R. A. and Daniel, B. (2008) 'Implications of a virtual learning community model for designing distributed communities of practice in higher education', in Communities of Practice: Creating Learning Environments for Educators, Volume 2. pp. 347-365 [Online]. Version. Available at: https://ebookcentral-proquestcom.ezproxy.lancs.ac.uk/lib/lancaster/reader.action?ppg=381\&doclD=4955965\&tm $=1537005479739$. . Accessed: 17 November 2018)

Silvey, V., Pejcinovic, L. and Snowball, T. (2018) 'Crossing divides: professional development for third space professionals', in Bossu, C. and Brown, N. (eds.) Professional and Support Staff in Higher Education. Singapore: Springer Singapore, pp. 1-16.

Sinfield, S., Holley, D., Burns, T., Hoskins, K., O'Neill, P. and Harrington, K. (2011) 'Raising the student voice: learning development as socio-political practice', in Hartley, P., Hilsdon, J., Keenan, C., Sinfield, S. and Verity, M. (eds.) Learning Development in Higher Education. Basingstoke: Palgrave Macmillan, pp. 53-63.

Spears, R. (2011) 'Group identities: the social identity perspective', in Schwartz, S.J., Luyckx, K. and Vignoles, V.L. (eds.) Handbook of identity theory and research. New York: Springer, pp. 201-224.

Spitzer, W. and Wedding, K. (1995) 'LabNet: An intentional electronic community for professional development', Computers and Education, 24(3), pp. 247-255. 
Steeples, C., and Goodyear, P. (1999) Enabling professional learning in distributed communities of practice: Descriptors for multimedia objects. Journal of Network and Computer Applications, 22(2), pp. 133-145.

Tajfel, H. (1974) 'Social identity and intergroup behaviour', Information (International Social Science Council), 13(2), pp. 65-93.

Tajfel, H. (1982) 'Social psychology of intergroup relations', Annu. Rev. Psychol., 33, pp139.

The Guardian (2017) 'Work in an academic-professional hybrid role? Say goodbye to career progression', 29 September. Available at:

https:/www.theguardian.com/higher-education-network/2017/sep/29/workacademic-professional-hybrid-role-say-goodbye-career-progression (Accessed: 18 November 2018).

Thomas, L. (2002) Building student engagement and belonging in Higher Education at a time of change: Final report from the What Works? Student Retention and Success programme. Available at:

https://www.heacademy.ac.uk/system/files/what works final report.pdf. (Accessed: 17 November 2018)

Turner, J. C. (1982) 'Towards a cognitive redefinition of the social group', in Tajel, H. (ed.) Social Identity and Intergroup Relations. Cambridge: Cambridge University Press, pp. 15-40.

Webster, H. (2017) 'Developing the developers', ALDinHE 2017: The Learning Development Conference, University of Hull, Hull 10-12 April.

Whitchurch, C. (2008) 'Shifting identities and blurring boundaries: the emergence of third space professionals in UK higher education', Higher Education Quarterly, 62(4), pp. 377-396. 


\section{Author details}

Katharine Stapleford is now a lecturer in Digital Education at the University of Leeds. She was an online learning tutor at Leeds Beckett university when she carried out this project. She is currently completing a $\mathrm{PhD}$ in E-research and Technology Enhanced Learning at Lancaster University for which this project constituted one of the module papers. 